\title{
Factors associated with institutional delivery service utilization in Ethiopia
}

\author{
This article was published in the following Dove Press journal: \\ International Journal of Women's Health \\ 12 September 2016 \\ Number of times this article has been viewed
}

\author{
Alemi Kebede' \\ Kalkidan Hassen ${ }^{2}$ \\ Aderajew Nigussie \\ Teklehaymanot ${ }^{1}$ \\ 'Department of Population and Family \\ Health, ${ }^{2}$ College of Health Sciences, \\ Jimma University, Ethiopia
}

\begin{abstract}
Background: Most obstetric complications occur unpredictably during the time of delivery, but they can be prevented with proper medical care in the health facilities. Despite the Ethiopian government's efforts to expand health service facilities and promote health institution-based delivery service in the country, an estimated $85 \%$ of births still take place at home.
\end{abstract}

Objective: The review was conducted with the aim of generating the best evidence on the determinants of institutional delivery service utilization in Ethiopia.

Methods: The reviewed studies were accessed through electronic web-based search strategy from PubMed, HINARI, Mendeley reference manager, Cochrane Library for Systematic Reviews, and Google Scholar. Review Manager V5.3 software was used for meta-analysis. Mantel-Haenszel odds ratios (ORs) and their 95\% confidence intervals (CIs) were calculated. Heterogeneity of the study was assessed using $I^{2}$ test.

Results: People living in urban areas $(\mathrm{OR}=13.16, \mathrm{CI}=1.24,3.68)$, with primary and above educational level of the mother and husband $(\mathrm{OR}=4.95, \mathrm{CI}=2.3,4.8$, and $\mathrm{OR}=4.43, \mathrm{CI}=1.14$, 3.36 , respectively), who encountered problems during pregnancy $(\mathrm{OR}=2.83, \mathrm{CI}=4.54,7.39)$, and living at a distance $<5 \mathrm{~km}$ from nearby health facility $(\mathrm{OR}=2.6, \mathrm{CI}=3.33,6.57)$ showed significant association with institutional delivery service utilization. Women's autonomy was not significantly associated with institutional delivery service utilization.

Conclusion and recommendation: Distance to health facility and problems during pregnancy were factors positively and significantly associated with institutional delivery service utilization. Promoting couples education beyond primary education regarding the danger signs of pregnancy and benefits of institutional delivery through available communication networks such as health development army and promotion of antenatal care visits and completion of four standard visits by pregnant women were recommended.

Keywords: systematic review, Ethiopia, institutional delivery, predictors, associated factors

\section{Introduction}

Utilization of essential obstetric care services, including but not limited to antenatal care (ANC), skilled attendants at birth and postnatal care, contributes to the reduction of maternal and neonatal mortality and morbidity in low-income countries. ${ }^{1,2}$ Approximately $75 \%$ or more of maternal deaths could be averted if all women had access to the interventions for preventing or treating pregnancy and birth complications, in particular emergency obstetric care. ${ }^{3}$ Institutional delivery service utilization is one of the key and proven interventions to reduce maternal death. It ensures safe birth, reduces both actual and potential complications and maternal death, and increases the survival of most mothers and newborns. ${ }^{4}$ 
In spite of the national and global efforts at reducing maternal morbidity and mortality through the safe motherhood initiative, there is no significant reduction in maternal morbidity and mortality in developing countries. ${ }^{5,6}$ Maternal mortality remains a major challenge to health care systems worldwide. Hence, improving maternal health has been on the global health agenda for many years. ${ }^{7}$

Globally, there were an estimated 289,000 maternal deaths in 2013, yielding an maternal mortality rate (MMR) of 210 maternal deaths per 100,000 live births. Developing countries account for $99 \%(286,000)$ of the global maternal deaths. Hemorrhage and hypertensive disorders are the leading causes of maternal mortality in developing countries. ${ }^{6}$ However, most of the maternal deaths are preventable if deliveries were overseen by skilled personnel. ${ }^{8}$ International conference on population and development aims at having at least $90 \%$ of deliveries attended by skilled health care providers by 2015 as a strategy in reducing maternal mortality. ${ }^{9-14}$ However, in developing regions, 40 million births were not attended by skilled health care personnel, in which over 32 million occurred in rural areas in 2012. Delivering at health care facilities enables women receive proper medical attention and care during childbirth. This is fundamentally encouraged as a single most important strategy in preventing maternal and neonatal deaths. In almost all countries where $>80 \%$ of deliveries are attended by health care professionals, MMR is $<200$ per 100,000 live births. ${ }^{15}$ There is disparity between developing and developed countries regarding maternal health care service utilization. In developed countries, $\sim 97 \%$ of the pregnant women receive ANC and almost all births (99\%) use skilled obstetric service during delivery, whereas in developing countries only $52 \%$ of pregnant women had four or more ANC visits during their pregnancy and skilled health personnel attended $68 \%$ of deliveries in 2012. Sub-Saharan Africa is the region with the lowest coverage of skilled delivery service utilization, with $53 \%$ of women having skilled delivery attendants. ${ }^{16}$

Despite the Ethiopian government's efforts to expand health service facilities and promote institution-based delivery service in the country, an estimated $85 \%$ of births still take place at home. This underutilization of maternal health care services by a sizeable proportion of women in Ethiopia results in insignificant decline of maternal mortality ratio. ${ }^{17,18}$ No substantial reduction in home or unskilled deliveries was observed, especially in the rural community of Ethiopia in which urban births are more likely than rural births to be delivered in a health care facility (63\% versus $10 \%$ ) and MMR in Ethiopia is 676 per 100,000 live birth. ${ }^{19}$ One critical strategy for reducing maternal morbidity and mortality is to ensure that every baby is delivered in a health care facility with the assistance of a skilled health care attendant. Therefore, to reduce maternal deaths, the most efficient strategy for lower-income countries is to promote childbirth at health care facilities with a referral capacity, as timely management and treatment can make the difference between life and death. ${ }^{20}$

As evidenced from previous studies, utilization of institutional delivery service was determined by educational status of mothers and their husbands, knowledge of health problems during pregnancy, ANC visits, mothers' place of residence, age of the mothers, and perceived distance to the nearest health care facility. ${ }^{21-26}$ However, there are several inconsistent reports of the findings regarding educational status of mother and maternal age, ANC visits, ${ }^{27-29}$ mothers' place of residence, ${ }^{30-33}$ knowledge of health problems during pregnancy, perceived distance to the nearest health facility, ${ }^{34}$ women's autonomy, ${ }^{29,35-37}$ and availability of radio or television (TV). ${ }^{34,36,38}$ Even though many individual studies conducted in Ethiopia identified determinants for institutional delivery service utilization, so far there was no systematic review to show pooled effect of the determinants. Therefore, the aim of this review was to summarize the findings of all relevant individual studies regarding the determinants for institutional delivery service utilization in Ethiopia, thereby making the available evidence accessible for decision makers (Figure 1).

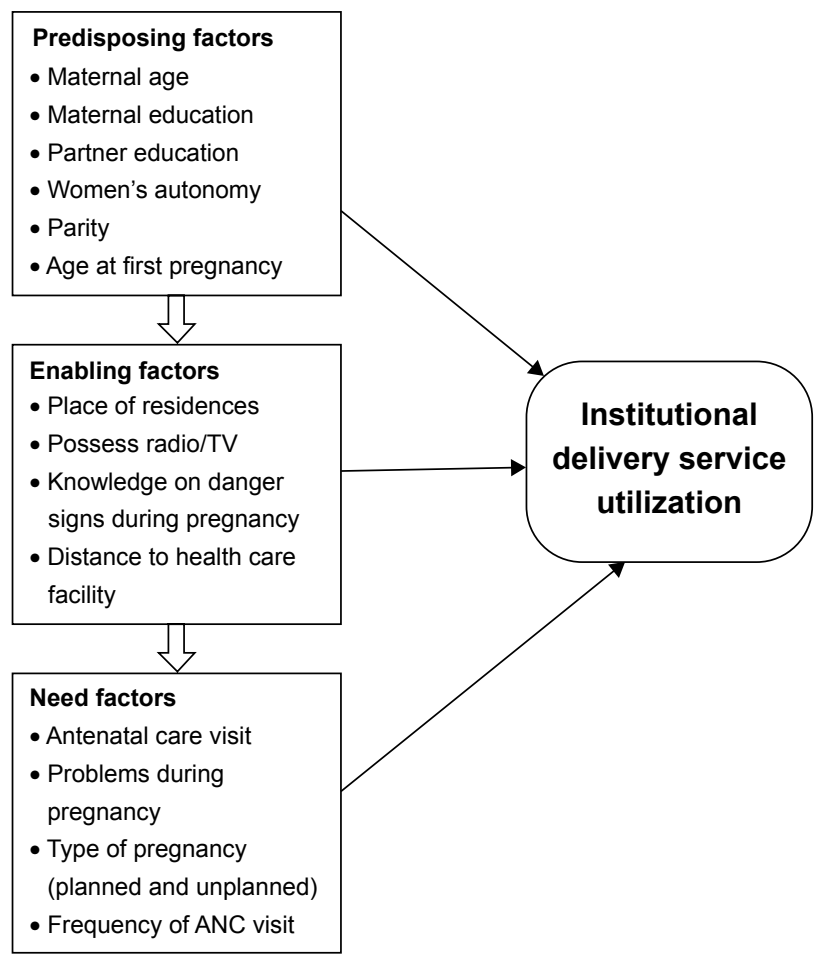

Figure I Conceptual framework.

Note: Data from references. . $^{4,41,52,56}$

Abbreviations: ANC, antenatal care; TV, television. 


\section{Materials and methods}

The study participants of interest in this review were women of reproductive age group, in the age range of 15-49 years, who have had at least one birth.

\section{Phenomena of interest}

The phenomena of interest of this review were epidemiological association of predisposing factors with institutional delivery service utilization, enabling factors with institutional delivery service utilization, and need factors with institutional delivery service utilization.

\section{Types of studies}

All observational study designs (cohort, case-control, and cross-sectional studies) that assessed predictors or determinants of institutional delivery service utilization were included in this review.

\section{Search strategy}

Literature search strategies were implemented with the aim of finding both published and unpublished primary studies conducted in Ethiopia from 2000 to 2014 on the determinants of institutional delivery service utilization. The reviewed studies were accessed through electronic web-based search strategy from PubMed, HINARI, Mendeley reference manager, Cochrane Library for Systematic Reviews, and Google Scholar. A three-step search strategy was utilized in this review. An initial limited search of PubMed and HINARI was undertaken followed by an analysis of the text words contained in the title and abstract and of the index terms used to describe the article. A second search was undertaken across all included databases using all identified keywords and index terms. Third, the reference list of all identified reports and articles were searched for additional studies, and only English language was included. Hand searching was conducted for studies in Jimma University libraries regarding topic of review.

\section{Study selection}

Articles were identified by first analyzing titles and abstracts for relevance and compliance with preset selection criteria. Relevant articles were classified as included and excluded. Full texts of articles categorized as included were extracted systematically by using a standardized data extraction tool from the Joanna Briggs Institute Meta-Analysis of Statistics Assessment and Review Instruments. The following search terms were used "determinants", "associated factors" and "predictors" with "Institutional delivery service utilization", "Facility based delivery" and "maternal health service utilization" using the Boolean logic (AND, OR).

\section{Assessment of methodological quality}

The scientific quality of selected studies was assessed. Standardized critical appraisal instruments from the Joanna Briggs Institute Meta-Analysis of Statistics Assessment and Review Instruments were used to assess the methodological quality of studies. According to Joanna Briggs Institute criteria's for assessing quality of primary studies, those primary studies that met $\geq 60 \%$ were included for meta-analysis. ${ }^{19}$ Any disagreements that arise were resolved through discussions and supported by evidence.

\section{Data collection}

Quantitative data were extracted from papers included in the review using the standardized data extraction tool. From all selected studies, the following data were extracted: name of author, year of publication, regions where the study was conducted, study design, sample size, and predictor variables assessed. Standardized data extraction tool from Joanna Briggs Institute Meta-Analysis of Statistics Assessment and Review Instruments were used.

\section{Data synthesis}

Synthesis was begun by constructing a clear descriptive summary of the included studies. This was done by tabulating details about name of author, year of study or year of publication, study design, and number of participants. Quantitative data were pooled in statistical meta-analysis using Review Manager Software V5.3. All the results were subject to double data entry. Association effect sizes and their 95\% confidence intervals (CIs) were calculated for analysis. Heterogeneity was assessed using the standard $I^{2}$ test.

\section{Data quality control measures}

Search beyond published literature was done to reduce the risk of publication bias, and the quality of the included studies was assessed by using standardized critical appraisal tool from the Joanna Briggs Institute Meta-Analysis of Statistics Assessment and Review Instruments.

\section{Ethical consideration}

Ethical approval letter was obtained from Ethical Review Board of Jimma University.

\section{Operational definitions and definitions of terms}

ANC visitor: If a woman visited health care facility during pregnancy for getting pregnancy-related service.

ANC nonvisitor: If a woman did not visit health institution during pregnancy for obtaining a service related to pregnancy. 
Close to health facility: If a woman travelled $<5 \mathrm{~km}$ to reach health care facility. ${ }^{39}$

Far from health facility: If a woman travelled $\geq 5 \mathrm{~km}$ to reach health care facility.

Home delivery: When a mother gave birth at her home or others' home (neighbor, relatives, or family) or when a birth takes place outside of health institution. ${ }^{23}$

Institutional delivery utilization: When a mother gave birth at health institution (health center, hospital, or private clinic). Knowledgeable: Women were considered knowledgeable about danger signs related to pregnancy if they scored above the mean or median of knowledge questions and not knowledgeable if otherwise. ${ }^{21}$

Woman's autonomy: If a woman decided on the place to give birth by herself or with her husband jointly.

Nonautonomous women: If decision regarding the place to give birth was made by others (husband only, mother-in-law, father-in-law, or other people).

\section{Results}

\section{Description of studies}

A total of 202 articles were retrieved. After removing duplicated retrievals, 82 articles remained, of which 41 were excluded during the initial assessment due to inconsistency with inclusion criteria set for the review. For the remaining 41 articles, abstracts were accessed and screened. However, three of the articles were removed because the outcome variables are not the same with the outcome measured by definition of the review. Finally, all the studies that fulfilled the eligibility criteria were included for meta-analysis. From a total of 34 articles that met inclusion criteria for meta-analysis, eight of the studies were grey literatures. Three out of the 34 studies used secondary data from Ethiopian demographic and health survey data. All of the studies that meet the inclusion criteria relayed on household survey (Figure 2).

\section{Predisposing factors that determined institutional delivery service utilization \\ Mother's age}

The age of the mother was significantly associated with institutional delivery service utilization. Younger mothers (aged $<25$ years) were 1.8 times more likely to deliver in health institution than older mothers ( $\geq 25$ years) (odds ratio $[\mathrm{OR}][95 \% \mathrm{CI}]=1.77[1.29,2.42])$. Heterogeneity test indicated $I^{2}=75 \%$, hence random effect model was assumed

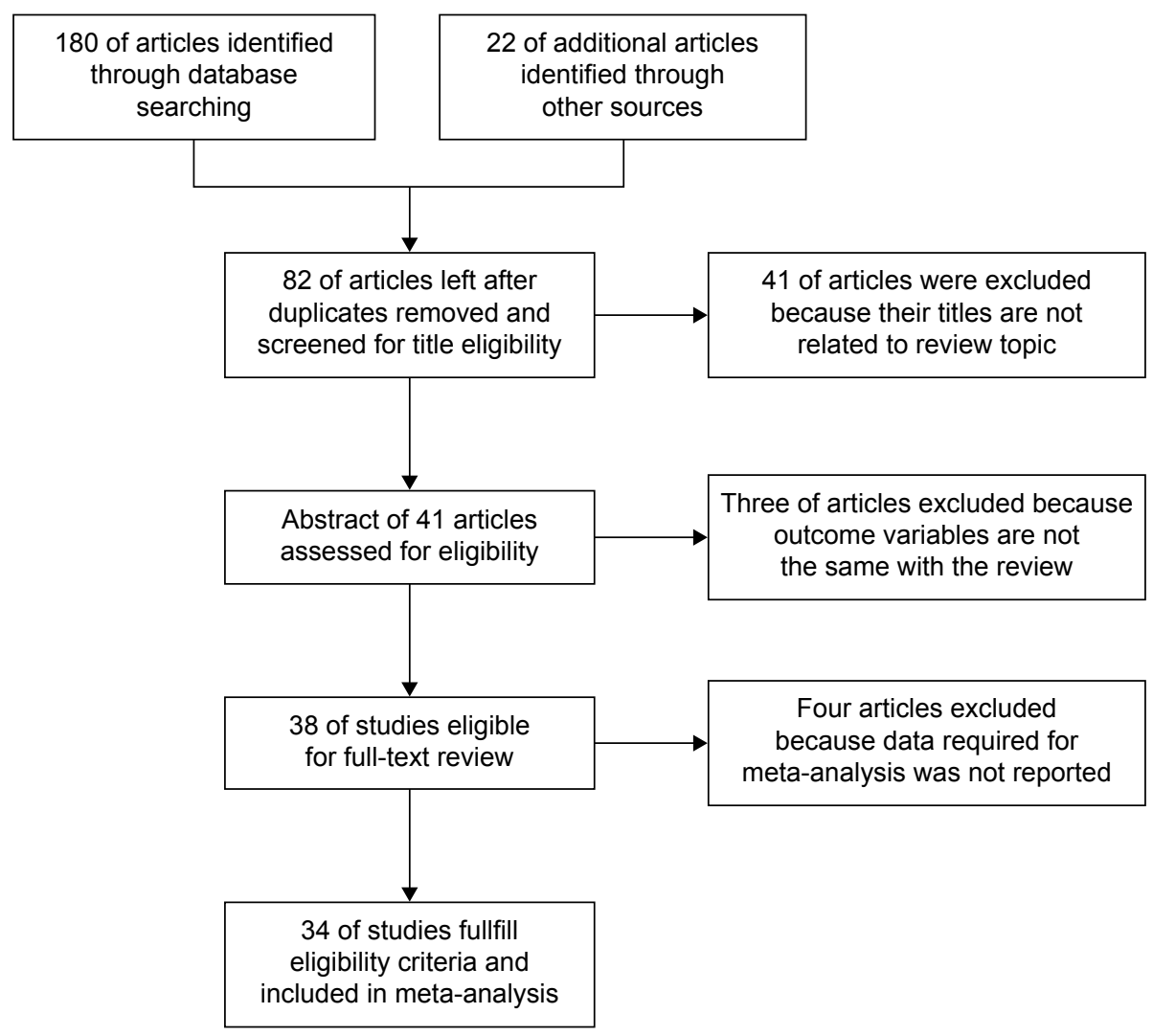

Figure 2 Description of study articles, 2014. 


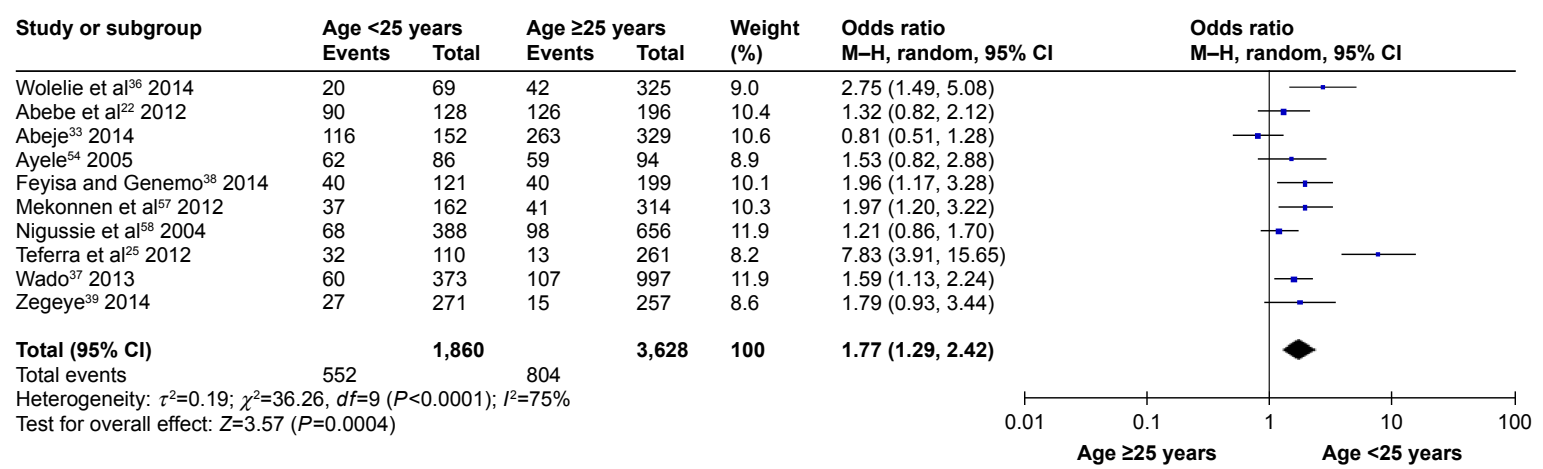

Figure 3 Association of maternal age with institutional delivery service utilization in Ethiopia, 2000-20I4.

Abbreviations: $\mathrm{Cl}$, confidence interval; $d f$, degrees of freedom; $\mathrm{M}-\mathrm{H}$, Mantel-Haenszel.

in the analysis. Sensitivity analysis was done, and no change was distinguished in the overall OR (Figure 3).

\section{Mother's educational level}

The findings of the review indicated significant association between mothers' educational status and utilization of institutional delivery service. Mothers who attended primary and above primary educational level were almost five times more likely to give birth at health institution than uneducated mothers $(\mathrm{OR}[95 \% \mathrm{CI}]=4.95[3.94,6.21])$. Heterogeneity test indicated $I^{2}=93 \%$, hence random effect model was assumed in the analysis. Sensitivity analysis did not bring significant change in the overall ORs (Figure 4).

\section{Husbands' educational level}

The chance of delivering in health facilities among those women whose husbands attended primary and above primary educational level were 4.4-fold higher than those

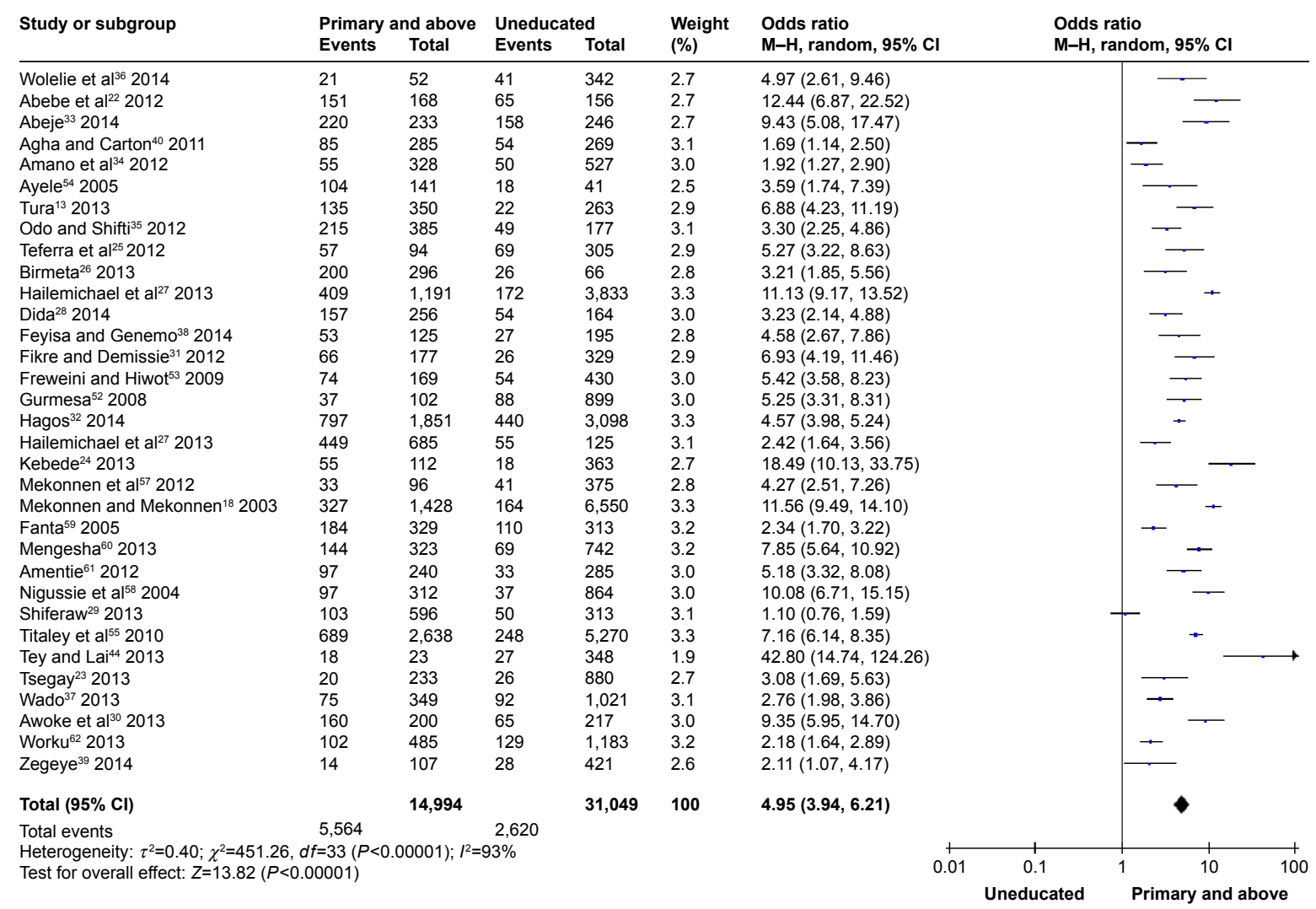

Figure 4 Educational status of the mother with institutional delivery service utilization in Ethiopia, 2000-20I4.

Abbreviations: $\mathrm{Cl}$, confidence interval; $d f$, degrees of freedom; $\mathrm{M}-\mathrm{H}$, Mantel-Haenszel. 


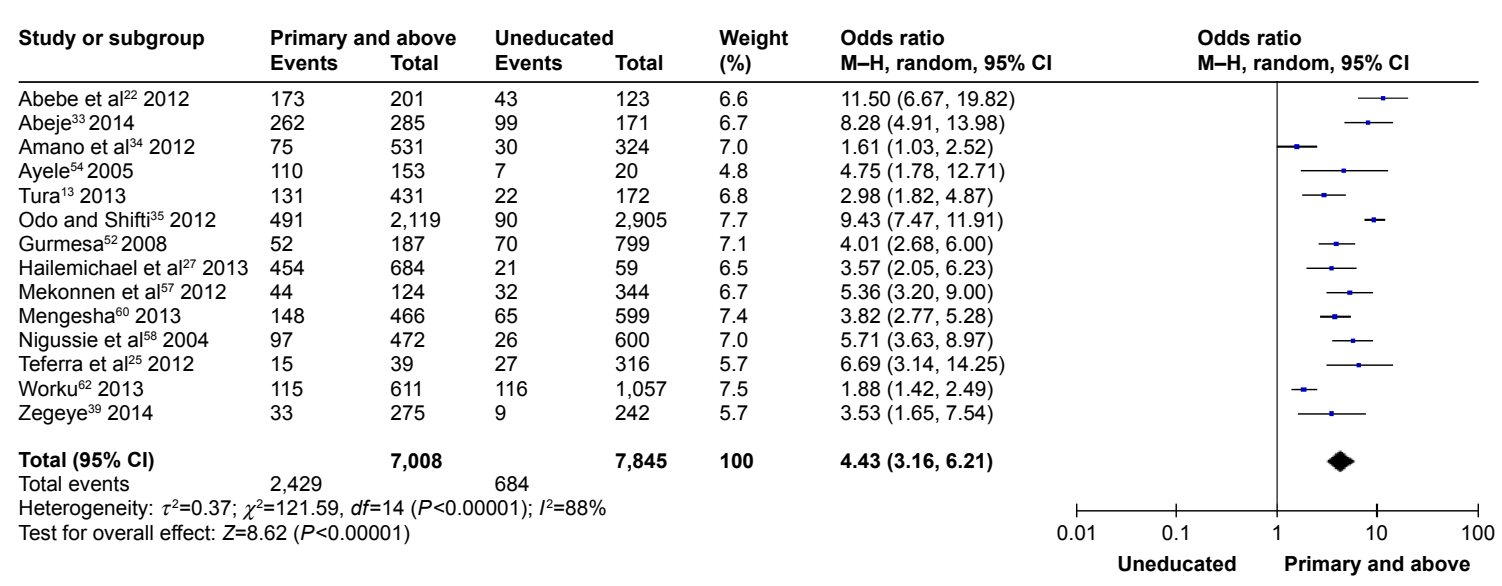

Figure 5 Educational status of the husband with institutional delivery service utilization in Ethiopia, 2000-2014.

Abbreviations: $\mathrm{Cl}$, confidence interval; $d f$, degrees of freedom; $\mathrm{M}-\mathrm{H}$, Mantel-Haenszel.

women whose husbands did not attend any educational level $(\mathrm{OR}[95 \% \mathrm{CI}]=4.43[3.16,6.21])$. Heterogeneity test indicated $l^{2}=88 \%$, hence random effect model was assumed in the analysis. Sensitivity analysis was done and revealed the stability of overall effect size (Figure 5).

\section{Women's autonomy}

The finding of this review showed insignificant association of utilization of institutional delivery service with women's autonomy (OR $[95 \% \mathrm{CI}]=0.8[0.47,1.36])$. Heterogeneity test indicated $I^{2}=95 \%$, hence random effect model was assumed during analysis. Sensitivity analysis was done, and no change was noted on overall OR (Figure 6).

\section{Parity}

Number of children the women delivered was significantly associated with institutional delivery service utilization. Women with parity 1 were three times more likely to give birth in health care facility than multiparous women (OR $[95 \% \mathrm{CI}]=3.05$ [2.68-3.49]). Heterogeneity test indicated $I^{2}=72 \%$, hence random effect model was assumed in analysis. Sensitivity analysis was done, and no significant change was observed in overall OR (Figure 7).

\section{Age at first pregnancy}

Age at first pregnancy was associated with institutional delivery service utilization. Women who had their first pregnancy after 20 years were 2.8 times more likely to give birth in health care facility than those who became pregnant before 20 years of age (OR [95\% CI] $=2.75[1.83,4.16])$. Heterogeneity test indicated $P=85 \%$, hence random effect model was assumed in the analysis. Sensitivity analysis was done and illustrated stability of overall OR (Figure 8).

\section{Enabling factors that determined institutional delivery service utilization} Residence

Findings of this review showed that residence setting (as defined by rural and urban) was one of the enabling factors that determined utilization of institutional delivery

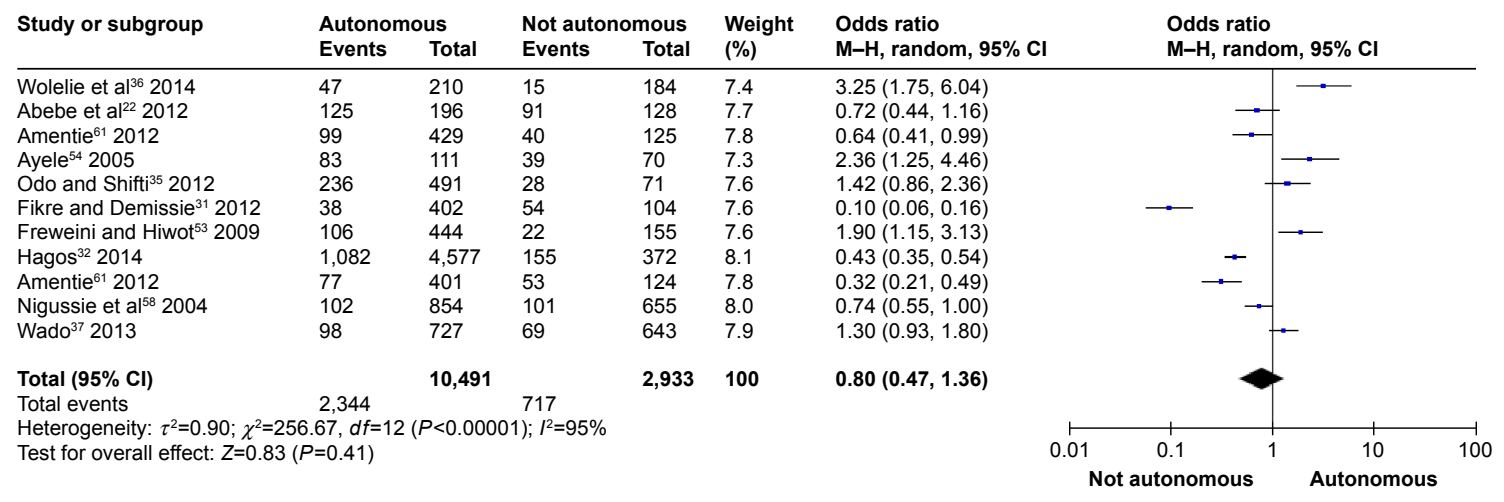

Figure 6 Association of women's autonomy with institutional delivery service utilization in Ethiopia, 2000-20I4. Abbreviations: $\mathrm{Cl}$, confidence interval; $\mathrm{df}$, degrees of freedom; $\mathrm{M}-\mathrm{H}$, Mantel-Haenszel. 


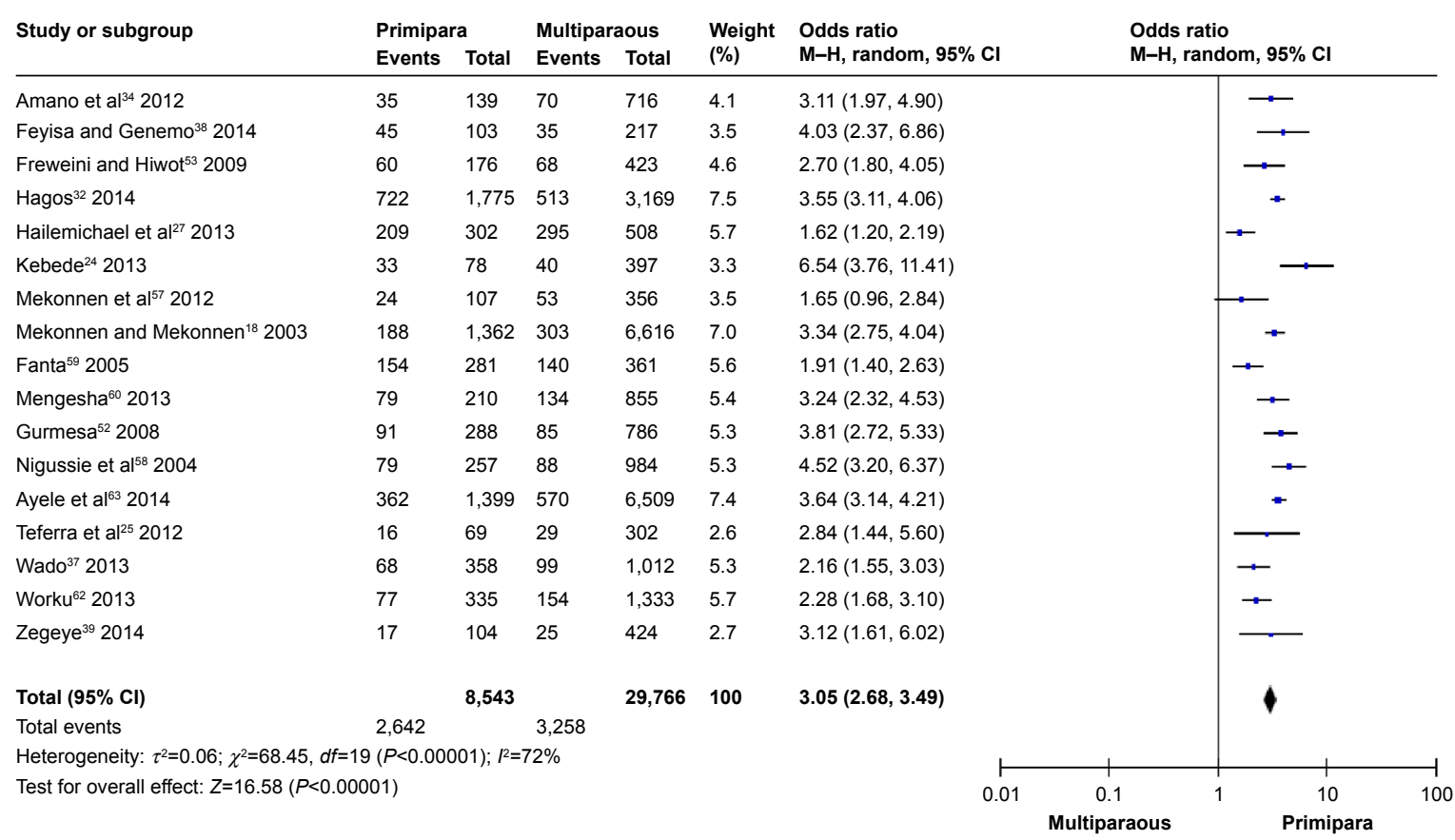

Figure 7 Association of parity with institutional delivery service utilization in Ethiopia, 2000-20I4.

Abbreviations: $\mathrm{Cl}$, confidence interval; $d f$, degrees of freedom; $\mathrm{M}-\mathrm{H}$, Mantel-Haenszel.

service. Women from urban area were 13.2 times more likely to deliver in health institution than women from rural area $(\mathrm{OR}[95 \% \mathrm{CI}]=13.16[9.44,18.35])$. Heterogeneity test indicated $I^{2}=95 \%$, hence random effect model was assumed in the analysis. Sensitivity analysis was done, and no change was noted in the overall OR (Figure 9).

\section{Knowledge of mothers regarding danger signs during pregnancy}

Knowledge regarding danger signs during pregnancy increased the probability of utilizing health institution for delivery service. Women who were knowledgeable about danger signs during pregnancy were 2.2 times more likely to give birth in health institution than those women who were not knowledgeable about danger signs during pregnancy $(\mathrm{OR}[95 \% \mathrm{CI}]=2.17[1.17,2.76])$. Heterogeneity test indicated moderate variability, $I^{2}=61 \%$, hence random effect model was assumed in the analysis. Sensitivity analysis was done, and no change was observed in the overall OR (Figure 10).

\section{Need factors that determined institutional delivery service utilization ANC visit}

ANC visit was the other factor that determined institutional delivery service utilization. Women who had at least one registered prenatal visit were five times more likely to utilize the service than those who did not visited

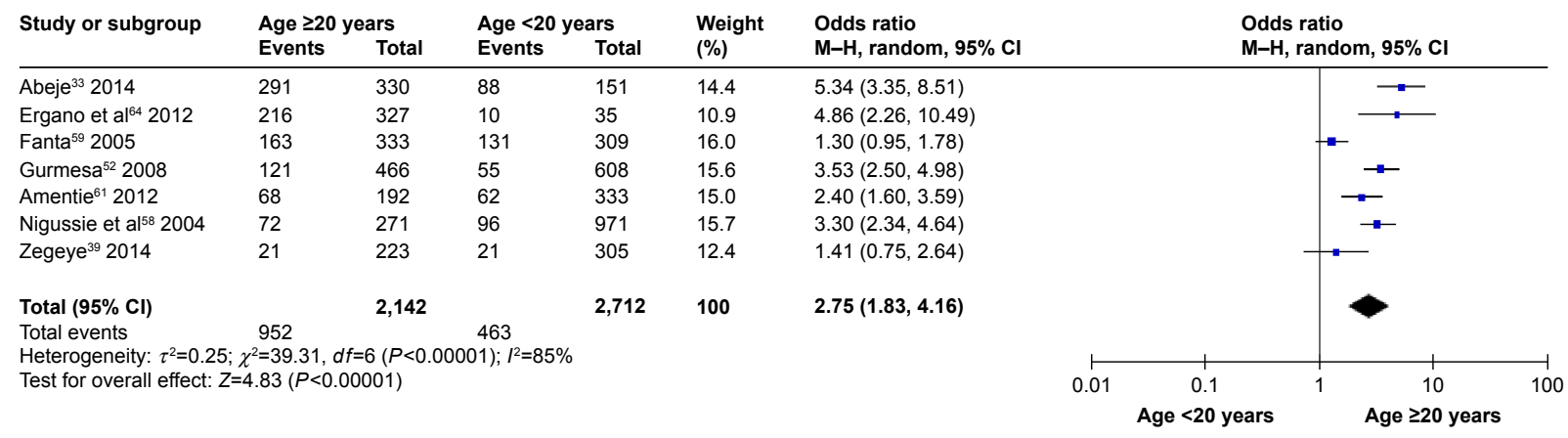

Figure 8 Association of age at first pregnancy with institutional delivery service utilization in Ethiopia, 2000-20I4. Abbreviations: $\mathrm{Cl}$, confidence interval; $d f$, degrees of freedom; $\mathrm{M}-\mathrm{H}$, Mantel-Haenszel. 


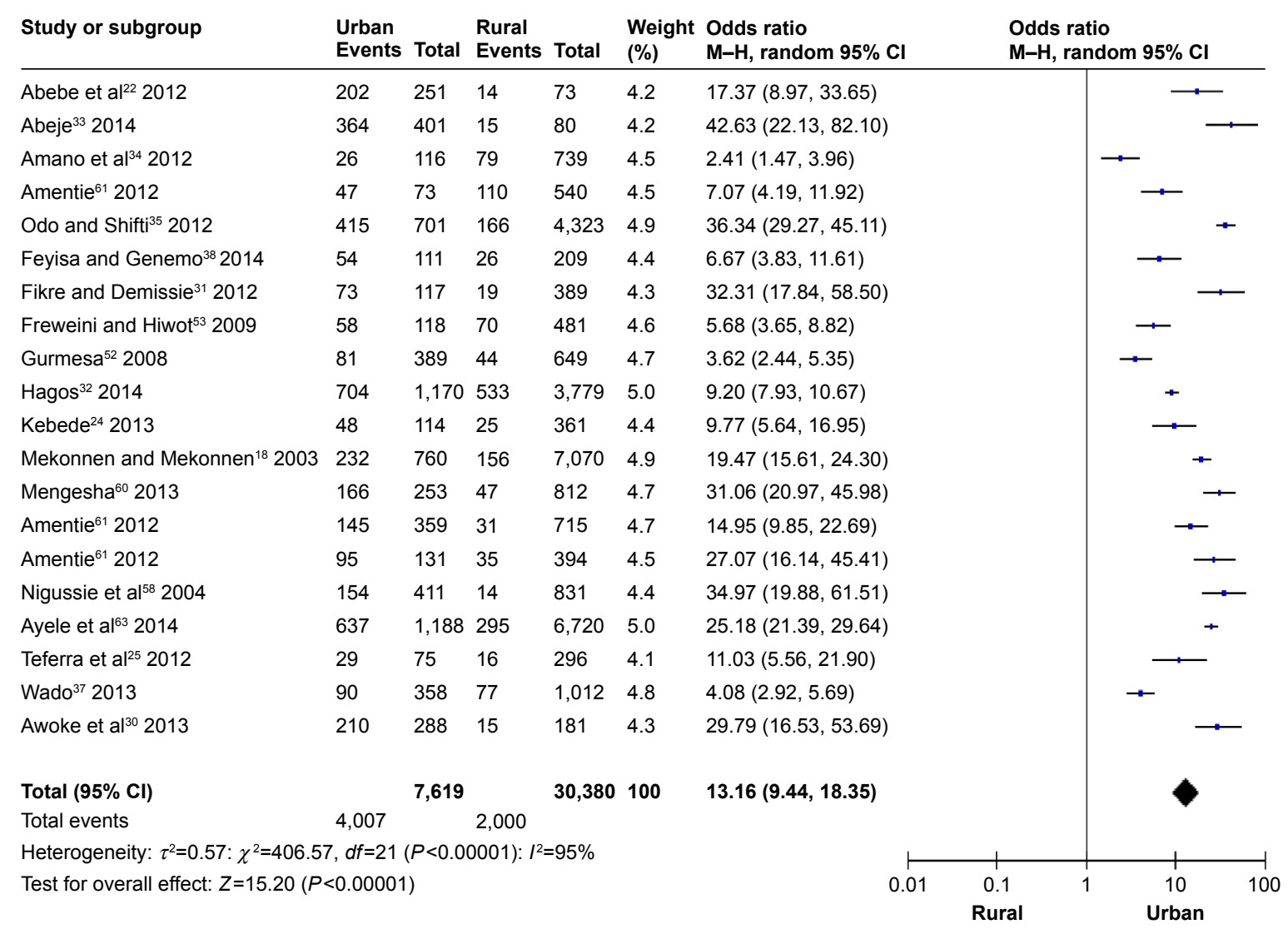

Figure 9 Association of place of residence on institutional delivery service utilization in Ethiopia, 2000-20I4.

Abbreviations: $\mathrm{Cl}$, confidence interval; $d f$, degrees of freedom; $\mathrm{M}-\mathrm{H}$, Mantel-Haenszel.

ANC during their pregnancy time $(\mathrm{OR}[95 \% \mathrm{CI}]=5.11$ $[4.55,5.72])$. Heterogeneity test indicated $I^{2}=88 \%$, hence random effect model was assumed in the analysis. Sensitivity test was done, and no change was noted on overall OR (Figure 11).

\section{Frequency of ANC visit}

Attending ANC as recommended by the World Health Organization (WHO) was also associated with institutional delivery service utilization. Women who attended ANC as recommended or four or more times were 3.2 times more

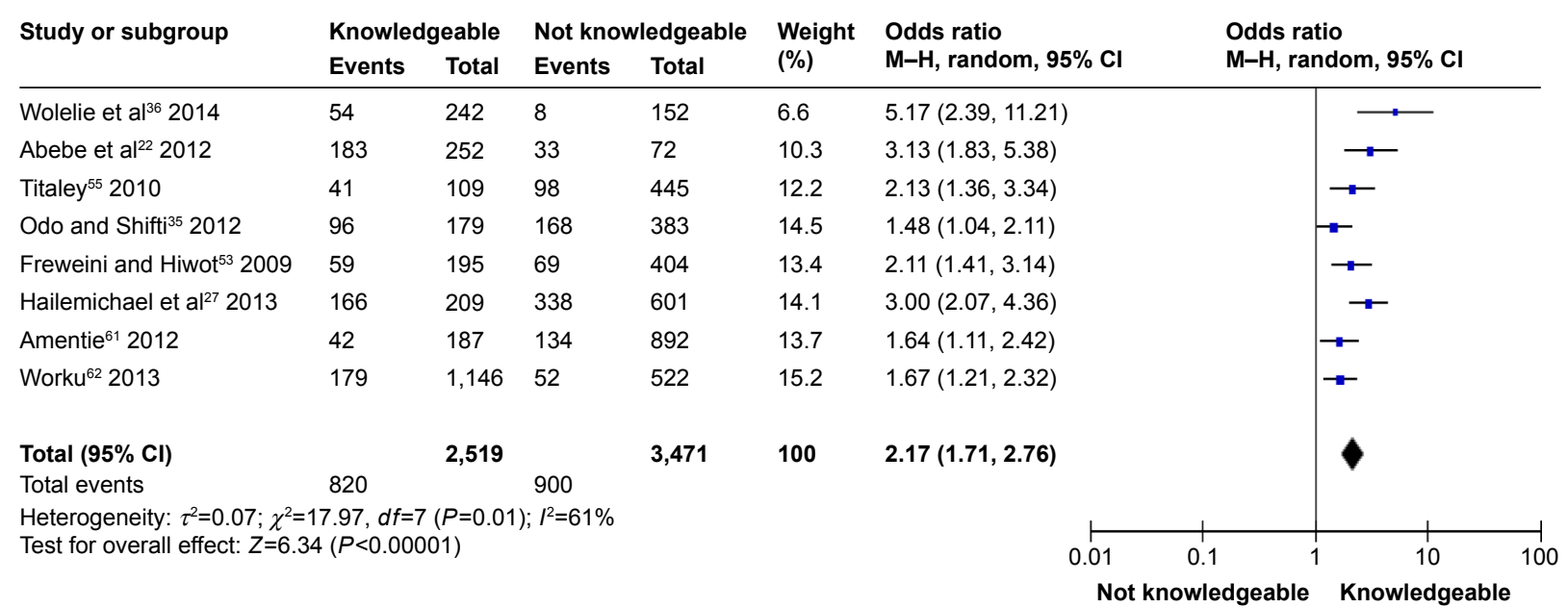

Figure 10 Association of knowledge of danger signs during pregnancy with institutional delivery service utilization in Ethiopia, $2000-2014$.

Abbreviations: $\mathrm{Cl}$, confidence interval; $d f$, degrees of freedom; $\mathrm{M}-\mathrm{H}$, Mantel-Haenszel. 


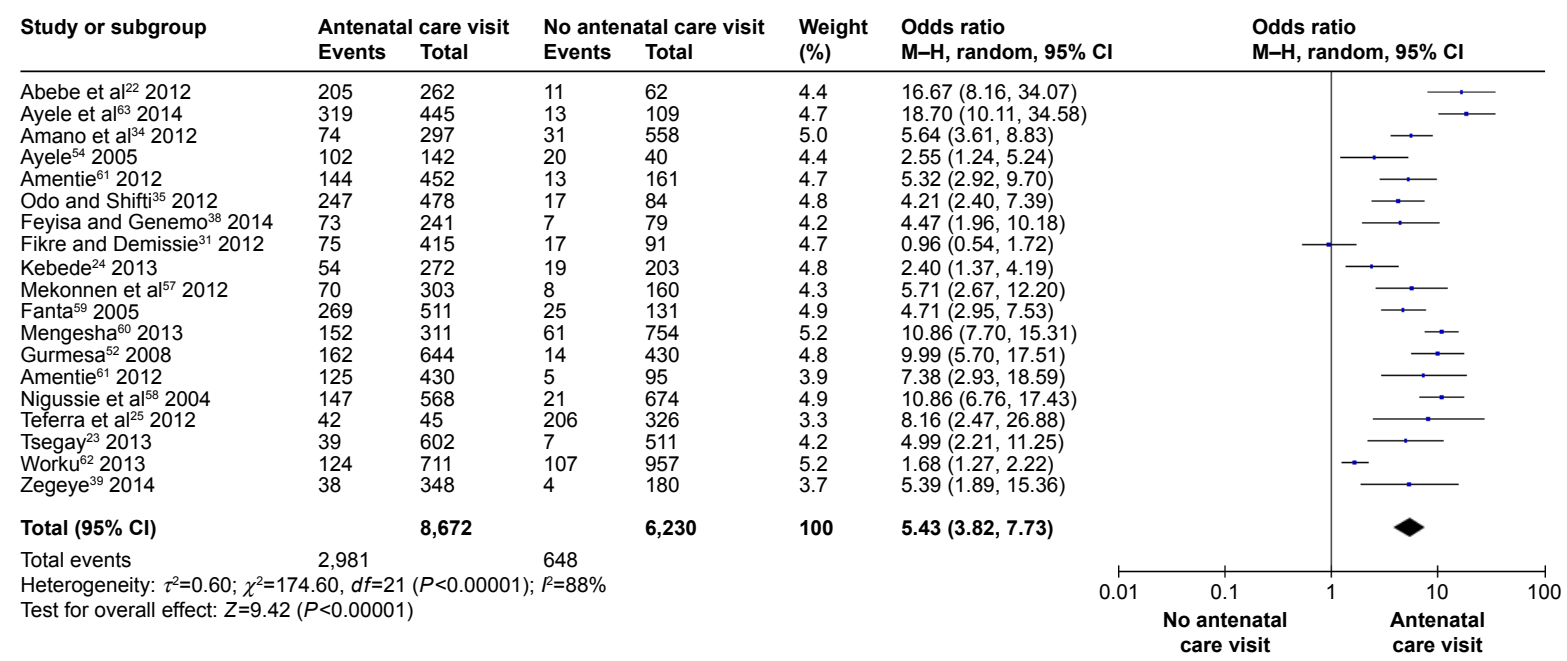

Figure II Association of antenatal care visit with institutional delivery service utilization in Ethiopia, 2000-20I4. Abbreviations: $\mathrm{Cl}$, confidence interval; $d f$, degrees of freedom; $\mathrm{M}-\mathrm{H}$, Mantel-Haenszel.

likely to give birth in health care facility than those women who attended ANC service below recommended times or less than four times (OR $[95 \% \mathrm{CI}]=3.24[2.07,5.09])$. Heterogeneity test indicated $I^{2}=92 \%$, hence random effect model was assumed in the analysis. Sensitivity test demonstrated stability of the overall OR (Figure 12).

\section{Type of pregnancy}

Type of pregnancy was another need factor that determined the probability of giving birth in health care facility. Those women who planned the pregnancy were 1.5 times more likely to give birth in health care facility than those women who did not plan the pregnancy $(\mathrm{OR}[95 \% \mathrm{CI}]=1.46$ $(1.25,1.71])$. Mild variability was observed among the included studies $\left(I^{2}=29 \%\right)$, thus fixed effect model was assumed in the analysis. Sensitivity analysis was done, and stability was noted in overall OR (Figure 13).

\section{Problems during pregnancy}

The findings illustrated that women who faced problems during pregnancy were 2.8 times more likely to utilize health care facility for delivery than those women who did not face problems during pregnancy $(\mathrm{OR}[95 \% \mathrm{CI}]=2.83$ $[1.48,5.38])$. Heterogeneity test indicated $I^{2}=93 \%$, hence random effect was assumed during analysis. Sensitivity analysis was done, and illustrated stability of overall OR (Figure 14).

\section{Discussion}

The findings of the review have revealed valuable information which is comparable with all the factors related to the outcome variable across the nation. The factors were related to predisposing, enabling, and need factors.

Level of mothers' education was found to be one of the determinants in this review ( $\mathrm{OR}=4.95)$. This finding

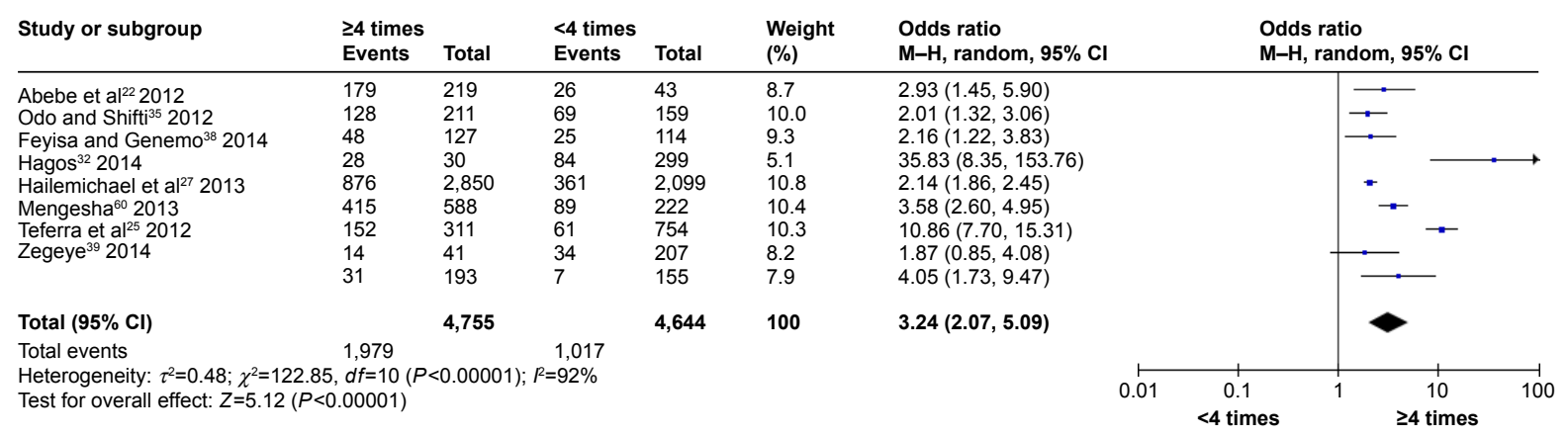

Figure 12 Association of frequency of antenatal care visit with institutional delivery service utilization in Ethiopia, $2000-2014$.

Abbreviations: $\mathrm{Cl}$, confidence interval; $d f$, degrees of freedom; $\mathrm{M}-\mathrm{H}$, Mantel-Haenszel. 


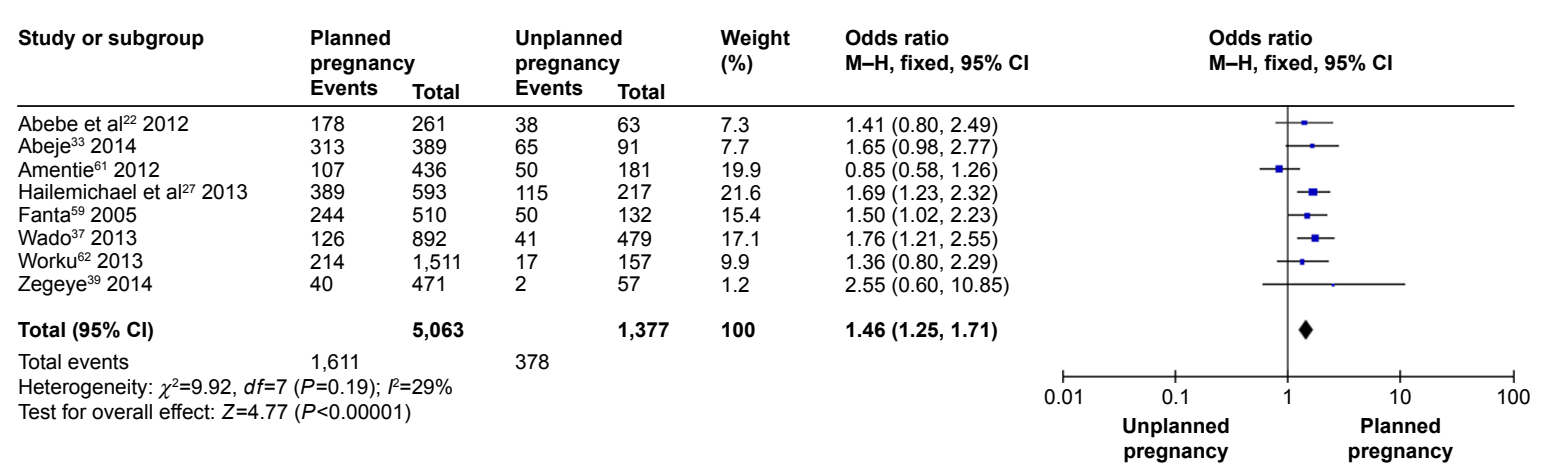

Figure 13 Association of type of pregnancy with institutional delivery service utilization in Ethiopia, 2000-20I4. Abbreviations: $\mathrm{Cl}$, confidence interval; $d f$, degrees of freedom; $\mathrm{M}-\mathrm{H}$, Mantel-Haenszel.

is consistent with primary studies done in Pakistan and Uganda $^{40,41}$ and systematic review in sub-Saharan Africa. ${ }^{42}$ As education makes mothers to be more concerned for their health and have more autonomy, their ability and freedom to make decisions about their own health is more favorable, which eventually enhance their health-seeking behavior. Education also improves the ability of educated women to afford the cost of medical health care service.

Education leads to better health awareness, which may sensitize the family to decide and utilize health care provided at various health care facilities. Therefore, husbands' educational status could also be favorable for timely health care seeking and economic capability required. Residence of the mothers was significantly associated with the utilization of institutional delivery service $(\mathrm{OR}=13.16)$. This finding was consistent with primary studies done in Uganda, Nigeria, and six selected South Asian and sub-Saharan African countries, which showed that urban/rural differences had significant associations with institutional delivery service utilization. ${ }^{41,43,44}$ This might be explained in terms of the characteristics of the urban residents, namely more proportion of educated mothers, availability of health care services nearby, and better access to information than rural mothers. Maternal age is also associated with institutional delivery service utilization $(\mathrm{OR}=1.77)$. The younger and the older women differ in their experience of the health-seeking behavior. The possible explanations might be that younger women are more likely to be literate and more likely to have knowledge on the benefits of health care facility delivery than older women. On the other hand, older women consider that giving birth at home is not risky as they have previously experienced birth at home.

This finding is also consistent with primary studies conducted in Nepal and three district of Tanzania. ${ }^{45,46}$ ANC services can provide opportunities for women to get information on the status of their pregnancy which in turn alerts them to decide where to deliver. In addition, use of ANC may signify the availability of a nearby health care service, which may also provide delivery care. Attending ANC as recommended by WHO were associated with institutional delivery utilization $(\mathrm{OR}=3.24)$. This is consistent with studies performed in southern Tanzania and Rwanda. ${ }^{47,48}$ Making the recommended four or more ANC visits might reflect the woman's concern of her pregnancy, pregnancy

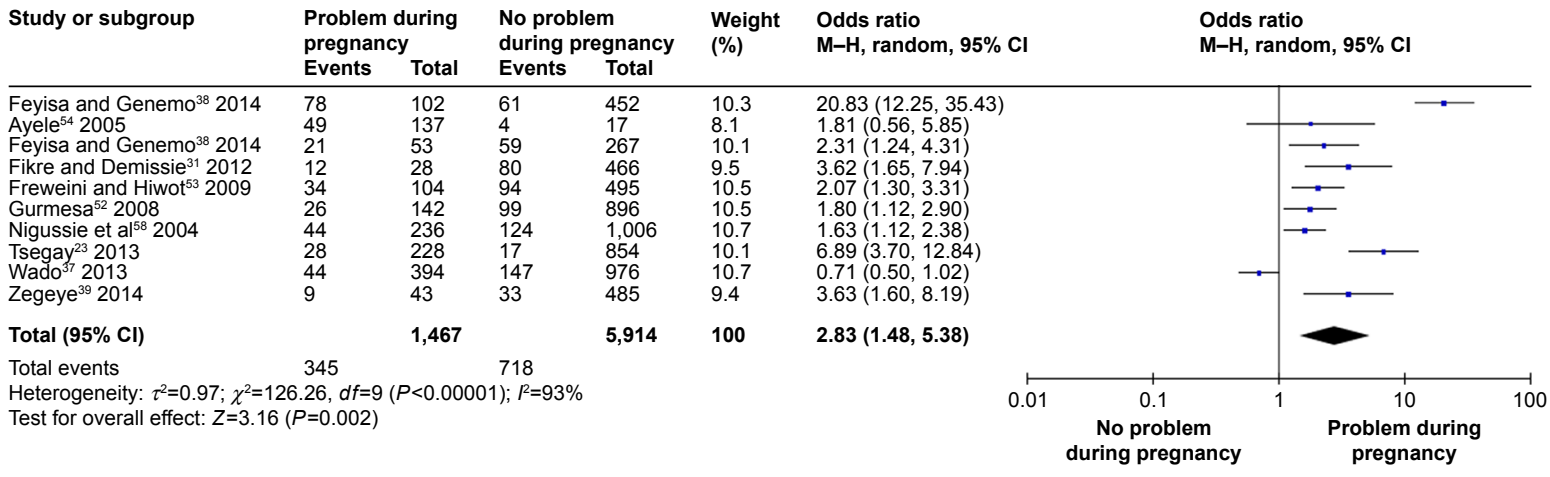

Figure I 4 Association of encountering problem with institutional delivery service utilization in Ethiopia, 2000-20I4.

Abbreviations: $\mathrm{Cl}$, confidence interval; $d f$, degrees of freedom; $\mathrm{M}-\mathrm{H}$, Mantel-Haenszel. 
complications, and the need for professional help and visiting ANC frequently increasing their familiarity with medical personal which expose the women to more health education and counseling which are more likely to increase the utilization of delivery service.

The result of the review revealed that women with parity 1 were more likely to give birth at health care facility than multiparous women $(\mathrm{OR}=3.05)$. This is consistent with a study conducted in Pakistan, a meta-analysis of sociodemographic factors predicting birth in health care facility conducted in developing countries, and a study in Philippines. ${ }^{40,49,50}$ The possible explanation for the low utilization of delivery care services among multiparous women could be because they feel more confident and perceive that there is no need for institutional delivery due to the experience and knowledge from previous pregnancies and births. Women with parity 1 were more motivated to deliver in health care facilities, which might be due to the fact that women who are pregnant for their first child are usually more likely to fear complication during labor and delivery than women of high parity and most of the times family members including husbands encourage and accompany their wives for maternal health care service for first time than for subsequent delivery. The finding of the review indicated that women who know danger signs during pregnancy were more likely to deliver at health care facility than those who do not know danger signs $(\mathrm{OR}=2.17)$. This is consistent with study done in Southern Tanzania that illustrated nearly threefold increase in skilled birth attendance when women has knowledge about risks during pregnancy (Addjested odds ratio [AOR] =2.95 (95\% CI 1.65, 5.25). ${ }^{47}$ The possible explanation might be, having knowledge of danger signs during pregnancy may influence women's perceptions about their susceptibility to and the seriousness of those complications and act as an impetus to obtain appropriate institutional delivery care. It is expected that a better informed individual was more likely to make reasonable decisions that increases utilization of delivery service that are provided at health care facility.

This finding is inconsistent with systematic review conducted in sub Saharan Africa (SSA), which stated that women with highest levels of autonomy most likely seek facility-based delivery. This might be due to the fact that the SSA review assesses power of the women in relation to other activities such as household purchase and freedom of movement in addition to decision on place of delivery. However, in four of studies included in the meta-analysis, autonomous women are less likely to deliver in health care facility. ${ }^{31,32,51,52}$ In three of the studies, the probability of delivering in health care facility was $\sim 1.90-4.33$ times higher among autonomous women than nonautonomous women. $21,36,53,54$

Problems encountered during pregnancy increased health institutional-based delivery service $(\mathrm{OR}=2.83)$. This finding is in agreement with the study conducted in Philippines and qualitative study conducted in Indonesia. ${ }^{50,55}$ The possible explanation might be that mothers who had history of problems have practical experience about the life treating care conditions than those who did not, this experience could motivate the mother to give birth in health care facility. In addition, experiencing the problem can make women seek health care services during pregnancy, and health care workers may then recommend health care facility delivery. The findings of the review showed that owning radio or TV increases birth in health care facility $(\mathrm{OR}=3.63)$. The possible explanation might be that having functional radio or TV may increase access to information related to maternal and neonatal health and service availability. And also mass media are effective in information dissemination, which could facilitate behavioral changes that might be allowing mothers for the acceptance and utilization of maternal health service.

\section{Conclusion}

The systematic review showed maternal age, residence setting, educational status of couples, owning radio/TV, parity, ANC visit, frequency of ANC visit, distance from nearby health care facility, type of pregnancy, age at first pregnancy, problem during pregnancy, and knowledge of danger signs during pregnancy as determinants for institutional delivery service utilization.

Residence setting, educational attainment, parity, ANC visit, frequency of ANC visit, possession of radio/TV, distance to health care facility, and problems during pregnancy were factors positively and significantly associated with institutional delivery service utilization. However, women's autonomy was not associated with institutional delivery service utilization.

\section{Acknowledgments}

Our special gratitude and appreciation goes to Jimma University for providing us Internet service to conduct the review, Population and Family Health Department, and all the authors of the original articles. Our thanks also go to Oromia Regional Health Bureau, Jimma University Library, and information communication technology for internet services.

\section{Disclosure}

The authors report no conflicts of interest in this work. 


\section{References}

1. Gabrysch S, Campbell OM. Still too far to walk: literature review of the determinants of delivery service use. BMC Pregnancy Childbirth. 2009;9:34.

2. Say L, Raine R. A systematic review of inequalities in the use of maternal health care in developing countries: examining the scale of the problem and the importance of context. 2007;85(10):812-819.

3. Wagstaff A, Claeson M. The Millennium Development Goals for Health: Rising to the Challenges. Washington (DC): The World Bank; 2004.

4. CSA [Ethiopia] and ICF International. Ethiopia Demographic and Health Survey 2011. Addis Ababa Ethiopia and Calverton, Maryland, USA: Central statistical Agency and ICF International; 2012.

5. Zureick-Brown S. Understanding global trends in maternal mortality. Int Perspect Sex Reprod Health. 2008;32-41.

6. WHO, UNICEF, UNFPA, The World Bank and United Nation Population Division. Trends in Maternal Mortality: 1990 to 2013; 2013. Available from http://www.who.int/reproductivehealth/publications/ monitoring/maternal-mortality-2013/en/. Accessed February 4, 2015.

7. World Health Organization (WHO). The World Health Report 2005. Make Every Mother and Child Count. Geneva: WHO; 2005: 500-507.

8. United Nation and African Union. Report on Progress in Achieving the Millennium Development Goals in Africa, 2013 Abidjan, Côte d'Ivoire; 2013.

9. World Health Organization (WHO). Fulfilling the Health Agenda for Women and Children Countdown to 2015 Maternal, Newborn and Child Survival; 2014.

10. CSA [Ethiopia] and ORC Macro. Ethiopia Demographic and Health Survey 2005. Addis Ababa, Ethiopia and Calverton, Maryland, USA: Central statistical Agency and ICF International; 2006.

11. CSA [Ethiopia] and ORC Macro. Ethiopia Demographic and Health Survey 2000. Addis Ababa, Ethiopia and Calverton, Maryland, USA: Central statistical Agency and ICF International; 2001.

12. Graham W, Bell J, Bullough W. Can skilled attendance reduce maternal mortality in developing countries? Stud HSO\&P. 2001;17:97-129.

13. Tura D. The effect of health facility delivery on neonatal mortality: systematic review and meta-analysis. BMC Pregnancy Childbirth. 2013;13(18):1471-2393.

14. UNFPA. Key Actions for the Further Implementation of the Program of Action of the ICPD $+5 ; 2008$. Available from www.unfpa.org. Accessed February 8, 2015.

15. UNFPA. Material Mortality updates; 2004. Delivering into Good Hands. Available from: http://www.unfpa.org/webdav/site/global/eng. pdf. Accessed February 8, 2015.

16. The United Nations (UN). The Millennium Development Goals Report. New York: UN; 2014.

17. Hailu M, Gebremariam A, Alemseged F, Deribe K. Birth preparedness and complication readiness among pregnant women in Southern Ethiopia. PLoS One. 2011;6(6):e21432.

18. Mekonnen Y, Mekonnen A. Factors influencing the use of maternal healthcare services in Ethiopia. J Health Popul Nutr. 2003;21(4): 374-382.

19. CSA [Ethiopia]. Ethiopia Mini Demographic and Health Survey 2014. Addis Ababa, Ethiopia; 2014.

20. World Health Organization. WHO 2012 Maternal and Child Health Fact Sheet; 2012. Available from: http://www.who.int/mediacentre/factsheets/ fs348/en/.world health Organization. Accessed December 27, 2014.

21. Abera M, Gebremariam A Belachew T. Predictors of safe delivery service utilization in Arsi Zone, South-East Ethiopia. Ethiop J Health Sci. 2011;21:96-106.

22. Abebe F, Berhane Y, Girma B. Factors associated with home delivery in Bahirdar, Ethiopia: a case control study. BMC Research Notes. 2012;5:653.

23. Tsegay G. Determinants of antenatal and delivery care utilization in Tigray region, Ethiopia: a cross-sectional study. Int $J$ Equity Health. $2013 ; 12: 30$
24. Kebede H. Use of previous maternal health services has a limited role in reattendance for skilled institutional delivery: cross-sectional survey in Northwest Ethiopia. Int J Womens Health. 2013;5:79-85.

25. Teferra AS, Alemu FM, Woldeyohannes SM. Institutional delivery service utilization and associated factors among mothers who gave birth in the last 12 months in Sekela District, North West of Ethiopia: A community-based cross sectional study. BMC Pregnancy Childbirth. 2012;12:74

26. Birmeta N. Determinants of maternal health care utilization in Holeta town, central Ethiopia. BMC Health Serv Res. 2013;13:256.

27. Hailemichael F, Woldie M, Tafese F. Predictors of institutional delivery in Sodo town, Southern Ethiopia. Afr J Prim Health Care Fam Med. 2013;5(1):544.

28. Dida N. Modeling the probability of giving birth at health institutions among pregnant women attending antenatal care in West Shewa Zone, Oromia, Ethiopia: a cross sectional study. Afr Health Sci. 2014; 14(2):288-298

29. Shiferaw K. Why do women prefer home births in Ethiopia? BMC Pregnancy Childbirth. 2013;13:5.

30. Awoke W, Muhammed J, Abeje G. Institutional delivery service utilization in Woldia. Ethiop Sci J Public Health. 2013;1(1):18-23.

31. Fikre AA, Demissie M. Prevalence of institutional delivery and associated factors in Dodota Woreda (district), Oromia regional state, Ethiopia. Reprod Health. 2012;9:33.

32. Hagos B. Utilization of institutional delivery service at Wukro and Butajera districts in the Northern and South Central Ethiopia. BMC Pregnancy Childbirth. 2014;14:1-11.

33. Abeje R. Factors associated with Institutional delivery service utilization among mothers in Bahir Dar City administration, Amhara region: a community based cross sectional study. Reprod Health. 2014; 21(4):374-382.

34. Amano A, Gebeyehu A, Birhanu Z. Institutional delivery service utilization in Munisa Woreda, South East Ethiopia: a community based cross-sectional study. BMC Pregnancy Childbirth. 2012; $12: 105$.

35. Odo DB, Shifti DM. Institutional delivery service utilization and associated factors among child bearing age women in Goba Woreda, Ethiopia. Pan Afr Med J. 2012;13(Suppl 1):17.

36. Wolelie A, Aychiluhm M, Awoke W. Institutional delivery service utilization and associated factors in Banja District, Awie Zone, Amhara Regional. Open J Epidemiol. 2014;4(1):30-35.

37. Wado M. Unintended pregnancies and the use of maternal health services in southwestern Ethiopia. BMC Int Health Hum Rights. 2013; $13: 36$

38. Feyisa TR, Genemo GA. Determinants of institutional delivery among childbearing age women in western Ethiopia, 2013: unmatched case control study. PLoS One. 2014;9(5):1-7.

39. Zegeye A. The role of geographical access in the utilization of institutional delivery service in rural Jimma Horro District, Southwest Ethiopia. Prim Health Care. 2014;4(1):150.

40. Agha S, Carton TW. Determinants of institutional delivery in rural Jhang, Pakistan. Int J Equity Health. 2011;10:31.

41. Kalule-Sabiti I, Amoateng AY, Ngake M. The effect of socio-demographic factors on the utilization of maternal health care services in Uganda. Popul Health. 2015;28(1):515-525.

42. Moyer CA, Mustafa A. Drivers and deterrents of facility delivery in subSaharan Africa: a systematic review. Reprod Health. 2013;10(1):1.

43. Babalola S, Fatusi A. Determinants of use of maternal health services in Nigeria - looking beyond individual and household factors. BMC Pregnancy Childbirth. 2009;13:1-13.

44. Tey N, Lai S. Correlates of and barriers to the utilization of health services for delivery in South Asia and Sub-Saharan Africa. Sci World J. 2013;2013:11

45. Karkee R, Lee AH, Vishnu K. Need factors for utilisation of institutional delivery services in Nepal: an analysis from Nepal Demographic and Health Survey. BMJ Open. 2014;4:e004372. 
46. Exavery A, Kanté AM, Njozi M, et al. Access to institutional delivery care and reasons for home delivery in three districts of Tanzania. Int $J$ Equity Health. 2014;13:48.

47. Mpembeni RN, Killewo JZ, Leshabari MT, et al. Use pattern of maternal health services and determinants of skilled care during delivery in Southern Tanzania: implications for achievement of MDG-5 targets. BMC Pregnancy Childbirth. 2007;7:1-7.

48. Joharifard S, Rulisa S, Niyonkuru F, et al. Prevalence and predictors of giving birth in health facilities in Bugesera District, Rwanda. BMC Public Health. 2012;12(1):1.

49. Yifru B. A meta-analysis of socio-demographic factors predicting birth in health facility. Ethiop J Health Sci. 2014;24(Suppl):81-92.

50. Shimazaki A. Factors associated with facility-based delivery in Mayoyao, Ifugao Province, Philippines. Asia Pac Fam Med. 2013;12(1):5.

51. Negalign B. Utilization of clean and safe delivery service package of health services extension program and associated factors in rural Kebeles of Kafa Zone, Southwest Ethiopia. Ethiop J Health Sci. 2013; 23(2):79-89.

52. Gurmesa T. Safe delivery service utilization in Metekel zone, Northwest Ethiopia. Ethiop J Health Sci. 2008;17(4):217-219.

53. Freweini G, Hiwot F. Assessment of Factors for Safe Delivery Service Utilization among Women of Childbearing Age in Ephratanagidim District, North Shoa Zone, Amhara Regional State, Ethiopia [master's thesis]. School of Graduate Studies of Addis Ababa University; 2009.

54. Ayele B. What Factors Determine Delivery Practices of Pregnant Women? School of Graduate Studies [master's thesis]. Addis Ababa University; 2005.

55. Titaley CR, Hunter CL, Dibley MJ, Heywood P. Why do some women still prefer traditional birth attendants and home delivery? A qualitative study on delivery care services in West Java Province, Indonesia. BMC Pregnancy Childbirth. 2010;10:43.

56. World Population Reference Bureau Data Sheet. Available from: http://www.prb.org/pdf14/2014-world-population-data-sheet_eng.pdf. Accessed January 11, 2015.

57. Mekonnen MG, Yalew KN, Jemal YU, Melese M. Determinants of delivery practices among Afar pastoralists of Ethiopia. Pan Afr Med J. 2012;13(Suppl 1):1-4.

58. Nigussie M, Mariam DH, Mitike G. Assessment of safe delivery service utilization among women of child bearing age in north Gondar zone, north west Ethiopia. Ethiop J Health Dev. 2004;18(3):145-152.

59. Fanta M. Assessment of Factors Affecting Utilization of Maternal Health Care Services in Ayssaita and Dubti Towns, Afar Regional State, North East Ethiopia [master's thesis]. Department of Community Health Faculty of Medicine, Addis Ababa University; 2005.
60. Mengesha K. Determinants of skilled attendance for delivery in Northwest Ethiopia: a community based nested case control study. BMC Public Health. 2013;13(1):130.

61. Amentie M. Utilization of Maternal Health Care Services and Influencing Factors among Women of Child Bearing Age in Assosa District, Benishangul Gumuz Regional State [master's thesis]. North West Ethiopia Department of Population and Family Health, Jimma University; 2012.

62. Worku D. Factors affecting utilization of skilled maternal care in Northwest Ethiopia: a multilevel analysis. BMC Int Health Hum Rights. 2013;13:20.

63. Ayele DZ, Belayihun B, Teji K, Ayana DA. Factors affecting utilization of maternal health care services in Kombolcha District, Eastern Hararghe Zone, Oromia Regional State, Eastern Ethiopia. Int Sch Res Notices. 2014;2014:7.

64. Ergano K, Getachew M, Seyum D, Negash K. Determinants of community based maternal health care service utilization in South Omo pastoral areas of Ethiopia. J Med Med Sci. 2012;3(2):112-121.

65. Mehari K. Determinant Factors Affecting Utilization of Maternal Health Care Services in Rural Ethiopia School of Graduate Studies [master's thesis]; Addis Ababa University; 2012.

66. Mezmur H. Factors Affecting Choice of Delivery Place among Women's in Haramaya Woreda, East Hararge Administrative Zone Ethiopia, School of Graduate Studies [master's thesis]. Addis Ababa University; 2011.

67. Jat TR, Ng N, San Sebastian M. Factors affecting the use of maternal health services in Madhya Pradesh state of India: a multilevel analysis. Int J Equity Health. 2011;10(1):59.

68. Yifru B, Berhan A. Antenatal care as a means of increasing birth in the health facility and reducing maternal mortality: a systematic review. Ethiop J Health Sci. 2014;6:93-104.

69. Bohren MA, Hunter EC, Munthe-Kaas HM, Souza JP, Vogel JP, Gülmezoglu AM. Facilitators and barriers to facility-based delivery in low-and middle-income countries: a qualitative evidence synthesis. Reprod Health. 2014;11:1-17.

70. Idris SH. Determinants of place of delivery among women in a semiurban settlement in Zaria, Northern Nigeria. Ann Afr Med. 2006;5(2): 68-72.

71. Sharma SR, Poudyal AK, Devkota BM, Singh S. Factors associated with place of delivery in rural Nepal. BMC Public Health. 2014; 14(1):306

72. Gabrysch S, Cousens S, Cox J, Campbell OM. The influence of distance and level of care on delivery place in rural Zambia: a study of linked national data in a geographic information system. PLoS Med. 2011;8(1):e1000394.
International Journal of Women's Health

\section{Publish your work in this journal}

The International Journal of Women's Health is an international, peerreviewed open-access journal publishing original research, reports, editorials, reviews and commentaries on all aspects of women's healthcare including gynecology, obstetrics, and breast cancer. The manuscript management system is completely online and includes

\section{Dovepress}

a very quick and fair peer-review system, which is all easy to use. Visit http://www.dovepress.com/testimonials.php to read real quotes from published authors. 